УДК 904

DOI: $10.17223 / 19988613 / 55 / 20$

\title{
И.В. Ованенко
}

\section{ОПЫТ РЕКОНСТРУКЦИИ ИСТОРИЧЕСКОГО КОСТЮМА НА ПРИМЕРЕ «ШАПКИ БУМАЖНОЙ»}

\author{
Статья выполнена при поддержке Программы конкурентоспособности Томского государственого университета.
}

\begin{abstract}
Изложена методика поэтапной натурной реконструкции шапки бумажной - разновидности боевого наголовья эпохи Средневековья - начала Нового времени, которая в том числе входила в комплекс защитного костюма служилых людей Сибири. Натурная реплика шапки бумажной полностью соответствует характеристикам исходного образца из коллекции оружейной палаты Московского Кремля и подобному типу боевых наголовий в целом. Методика реконструкции может быть использована при создании различных атрибутов исторического защитного костюма, находившихся на вооружении средневековых сообществ Северной Евразии.

Ключевые слова: защитный костюм; боевое наголовье; шапка бумажная; натурная реконструкция; поэтапная методика.
\end{abstract}

«Историческая реконструкция как научная деятельность является частью экспериментальной археологии, суть которой - воссоздание не простого подобия вещей, но их практических качеств, чтобы они могли служить по прямому назначению: костюм, чтобы носить, в котле варить пищу, кресалом - добывать огонь, оружием сражаться, доспех использовать для защиты» [1]. Актуальность исторических реконструкций обусловлена как необходимостью изучения прошлого, так и возросшей потребностью современного общества в его визуализации. Наиболее полной является натурная реконструкция, которая позволяет восстановить не только форму предмета или объекта, но и технологию их изготовления. Для адекватного воспроизведения исторического прототипа необходимо иметь надежную источниковую и методическую базу.

Важная роль в воссоздании зрительного образа исторической эпохи и облика общества принадлежит исторического костюму, в том числе такой его разновидности, как военный костюм.

Данная статья является частью работы по натурной реконструкции защитного снаряжения служилых людей по прибору (новобранцев из других сословий, не имеющих собственного военного костюма и вооружения) в Сибири в конце XVI - начале XVIII в. Автор обращается к одному из атрибутов военного костюма средневековой Руси, а именно шапке бумажной - защитному головному убору. Источниками для реконструкции служат описания, изображения, музейные экспонаты. Необходимость натурной реконструкции вызвана разнообразием типов защитных головных уборов, в том числе шапок бумажных, неполнотой описаний и изображений, физическими утратами на сохранившихся оригиналах. Физическая модель дает наиболее полное представление об артефакте, в том числе об особенностях технологических приемов изготовления, раскрывает значение каждого компонента в комплекте защитного снаряжения и взаимосвязь между ними, а также позволяет провести апробацию, например в ходе ролевой военной игры.

Важная информация о шапке бумажной содержится в работах А.В. Висковатова, Ф.Г. Солнцева, С. Герберштейна. По А.В. Висковатову, «шапка бумажная - головной убор, выполняющий защитные функции. Это были стеганые шапки, из сукна, шелковых или бумажных (хлопок) материй, с толстой хлопчатобумажной или пеньковой подкладкой. В подкладку иногда помещались куски от панцирей или кольчуг. Также они имели металлический наносник» [2. С. 273]. По Ф.Г. Солнцеву, шапка бумажная «представляла собой наиболее дешевый военный головной убор в России до XVII в., поэтому встречалась довольно редко, используясь в основном беднейшей частью военного сословия. Использовались они в качестве шлема и у некоторых кочевников, в частности - калмыков(рис. $1, a, \sigma) \ldots$ Судя по всему, куячная шапка и “шапка бумажная" - разные виды одного и того же защитного оголовья, просто первая была усилена стальными пластинками, а вторая была облегченным и более дешевым вариантом... Также известны внешне очень похожие на “шапки бумажные" так называемые “куячные”, или “куяшные шапки”, которые представляли собой пластинчато-нашивной доспех бригантинного типа, аналогичный куяку. Как и сами куяки, как правило, они имели восточное происхождение» [3. С. 187]. С. Герберштейн упоминает о шапках бумажных в таком ключе: «По защитным свойствам “шапка" была схожа с тегиляем - надежной защиты не давала, но все же, по свидетельствам современников, могла задержать стрелу» [4. С. 382].

Роль шапки бумажной раскрывает в своей работе О.В. Шиндлер: «Еще одним видом “шапок” были шапки бумажные и шапки куячные. Шапками бумажными, или куячными, называли шлемы монгольского или калмыцкого происхождения. Они были сделаны из плотно простеганной материи с вшитыми металлическими 
деталями, а также имели металлическую подвижную стрелку, защищавшую нос. Проводя аналогию между защитой головы и защитой корпуса, можно было бы выделить “мягкие” шлемы в отдельную группу, как мы это сделали с тегиляями. Однако, с нашей точки зрения, этого делать этого не стоит. В отличие от тегиляев, одного из самых распространенных доспехов XVI в., шапки бумажные почти не имели распространения в поместном войске...» [5. С. 167-219].

В качестве прототипа для реконструкции выбран экспонат под № 4463 «Шапка бумажная» из Оружейной палаты. Она имеет следующее описание: «Подшоломник из красного атласа, стегана хлопчатобумажной тканью с круглыми чешуйками в шахматном порядке. По стежкам прошит серебряною каймой, а по чешуйкам закрашен вышивкой серебряной, подклад атласный, был выкрашен в алый цвет» [6. С. 165].

История этого экспоната следующая. Этот подшоломник поступил в Московскую Оружейную палату в 1766 г. вместе с гардеробом Императора Петра II. И в описи обозначен так: «Шишак атласный красный, стеганый, шит серебром и золотом». В реестре 1775 г. этот экспонат записан на л. 218 под шифром Д-25. В описи 1808 г. - в ч. 2 на с. 2 С0 под № 2228. В описи 1835 г. записан вместе с куячными шапками и назван так же, как они, бумажным шишаком (См. ч. IV, с. 651 № 5623).
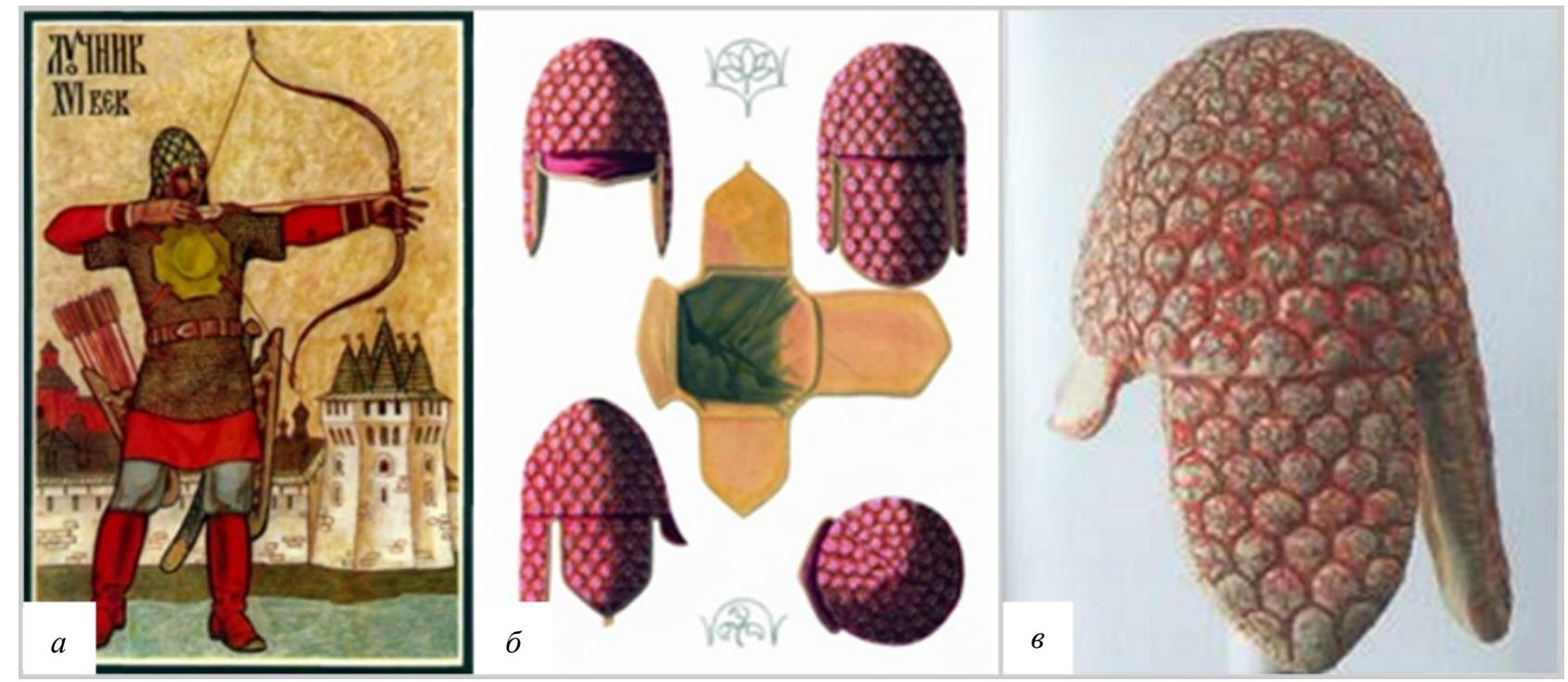

Рис. 1. Изобразительные источники:

а) Семенов В., Русские доспехи X-XVII веков. М. : Изобразительное искусство, 1983. Лучник. XVI век; б) Солнцев Ф. Г., Древности Российского государства. М., 1853. Отд. ІІІ. Л. № 31. Шелковая шапка; в) Московская оружейная палата. Экспонат № 4463

В делах Архива Московской Оружейной Палаты о подшоломниках упоминается только один раз: в Росписи оружия, выданного для смотра на Девичьем поле. В описи значится: «1664 года Февроля 1 дня. По Указу великого Государя и по приказу окольничего и оружейного Богдана Матвеевича Хитрово отпущено из оружейной Палаты в село Семеновское на потешный двор для его смотру Сокольникам 57 шапок Колмыцких и 57 подшеломников суконных розных цветов» (рис. 1, в) [6. С. 165].

Анализ данных приводит к выводу о том, что шапка бумажная - это обобщающее название отдельного кластера легкого защитного головного убора. Она использовалась в основном необеспеченными слоями воинского сословия. Шапка бумажная могла выступать как в роли самостоятельного защитного элемента, так и в роли подшлемника (мягкой основы под металлическую часть другого шлема). Имеет восточное происхождение, но была в обиходе и в русском войске и, скорее всего, использовалась служилыми людьми по прибору в Сибири в XVI-XVII вв. Артефакт, взятый за основу реконструкции, является частью гардероба императора Петра II, из-за чего имеет ряд статусных особенностей: употребление дорогих тканей - атласа, бархата, золотой и серебряной нитей, печать на ткани растительного орнамента. Учитывая, что служилые по прибору не могли себе позволить излишеств, их защитный костюм не имел статусных украшений. В связи с этим при реконструкции учтены основные параметры артефакта: общий вид, технология, защитные свойства.

При реконструкции шапки бумажной использовалась технология, максимально приближенная к исторической.

Mатериаль. Техническая вата, лен, хлопчатобумажные ткани, мешковина, шерстяные нитки, обработанные воском.

Выкройка. Выкройка должна соответствовать размерам головы. Бумажные модели выкроек выполняются без припусков на швы. Не забывайте, что изделие будет с наполнителем. Бумажная выкройка состоит из восьми частей. Из четырех частей подтреугольной формы собирается купол подшоломника, из двух изготавливаются нащечники и по одной части - козырек и защита шеи (рис. 2, а). По бумажным моделям выкраивается также подклад шапки бумажной. Затем идет раскрой изделия на ткани - с небольшим техническим запасом в 13 см. Ко всем деталям необходимо прибавить 1 см по краю на швы (рис. 2, б). Затем детали вырезаются (рис. 2, г). 

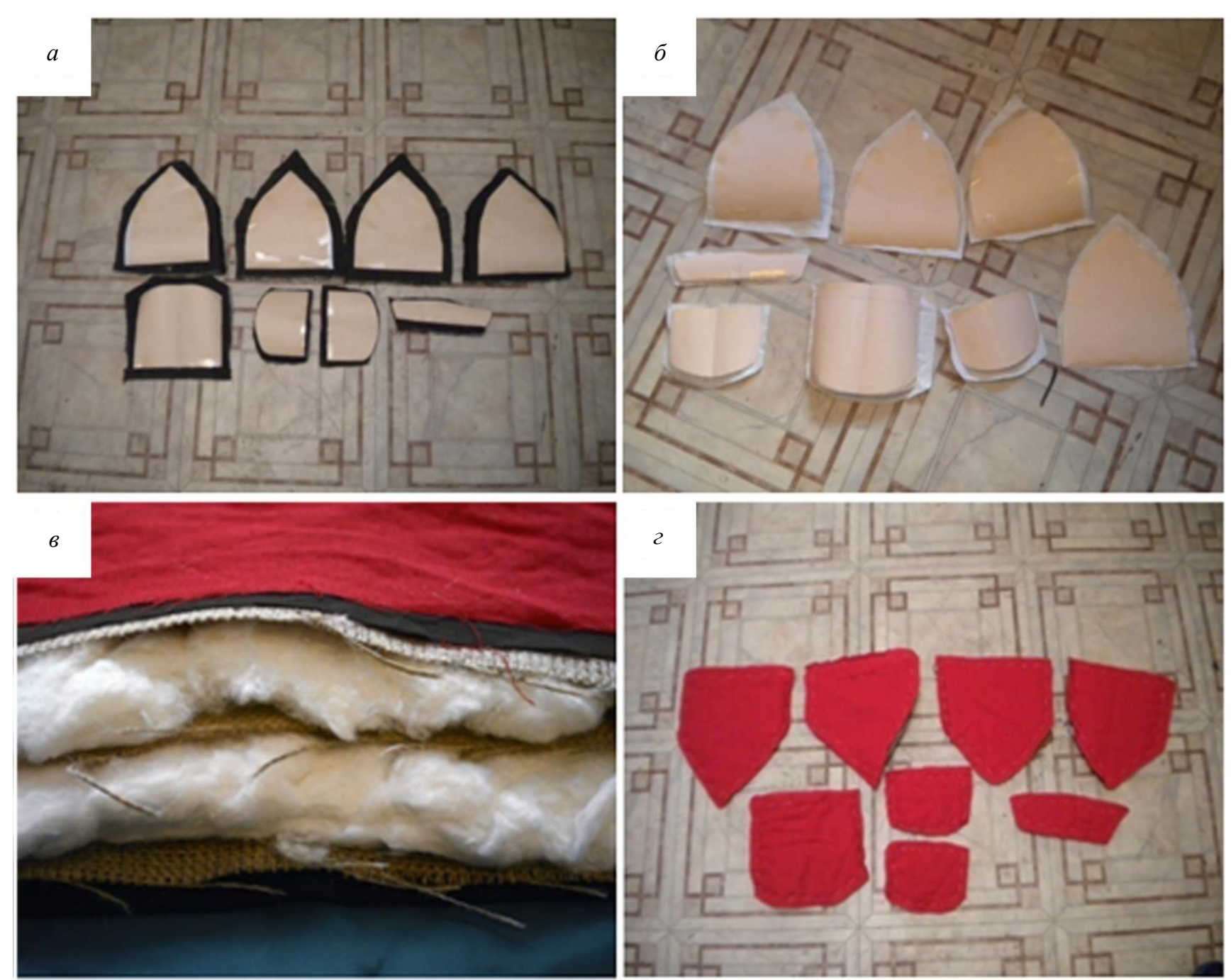

Рис. 2. Раскрой и наполнение шапки бумажной:

а) раскрой основного элемента шапки бумажной; б) раскрой подклада шапки бумажной;

в) наполнение шапки бумажной; г) сбор всех слоев в части основного элемента шапки бумажной

Простежка. После раскроя детали простегиваются (1 см по периметру всех деталей, оставленный на сборку, не надо простегивать, этот припуск уйдет в швы, чтобы части «сошлись» с минимальным зазором).

Складываем изнанку и лицо, прокладывая между ними набивку, состоящую из льна, мешковины и технической ваты (рис. 2, в), и скрепляем булавками по центру в нескольких местах. Здесь пригодятся выкройки без припусков. Если припуск давался только при переносе на ткань, то на всех лицевых деталях должно быть две линии: одна без учета припусков (вспомогательная линия), другая - линия обреза (с припусками). В пределах вспомогательных линий начинаем простегивать детали полуокружностью радиусом 125 мм в шахматном порядке, начиная с низа детали. Детали простегиваются вощеной шерстяной нитью (рис 3, б). Когда детали простеганы по вспомогательной линии, обрезаем наполнения. После этого по линии обреза отрезаем технический запас, который предназначен для того, чтобы устранить возможные нестыковки и сдвиги между изнаночным и лицевым слоями и материалом набивки. Срезы на краях деталей подгибаются лицевой стороной наизнанку. На изнанке остатки материала на швах обрезаются, чтобы не топорщились (рис. 3, в, г). Подклад сшивается аналогично основной части (рис. $3, \partial$ ).

Затем все детали наружной и подкладочной частей шапки бумажной сшиваются, используя технику «назад иголка» (рис. 3, a).

1. Начертите на ткани линию. Выведите нитку на лицевую сторону в точке $A$, немного отступив от конца начерченной линии.

2. Проведите иглу через точку $B$ в конце отмеченной линии и выведите ее в точке $C$. Расстояние от точки $A$ до точки $C$ должно быть равно расстоянию от точки $A$ до точки $B$.

3. Подтяните нитку.

4. Проведите иглу через точку $A$ и выведите ее в точке $D$. Расстояние от точки $C$ до точки $D$ должно быть равно расстоянию от точки $A$ до точки $C$.

5. Продолжайте выполнять стежки аналогичным образом, стараясь делать их одинаковой длины.

6. Чтобы закончить работу, проведите иглу на изнаночную сторону через отверстие в начале предыдущего стежка. Подтяните нитку и закрепите ее [7]. 

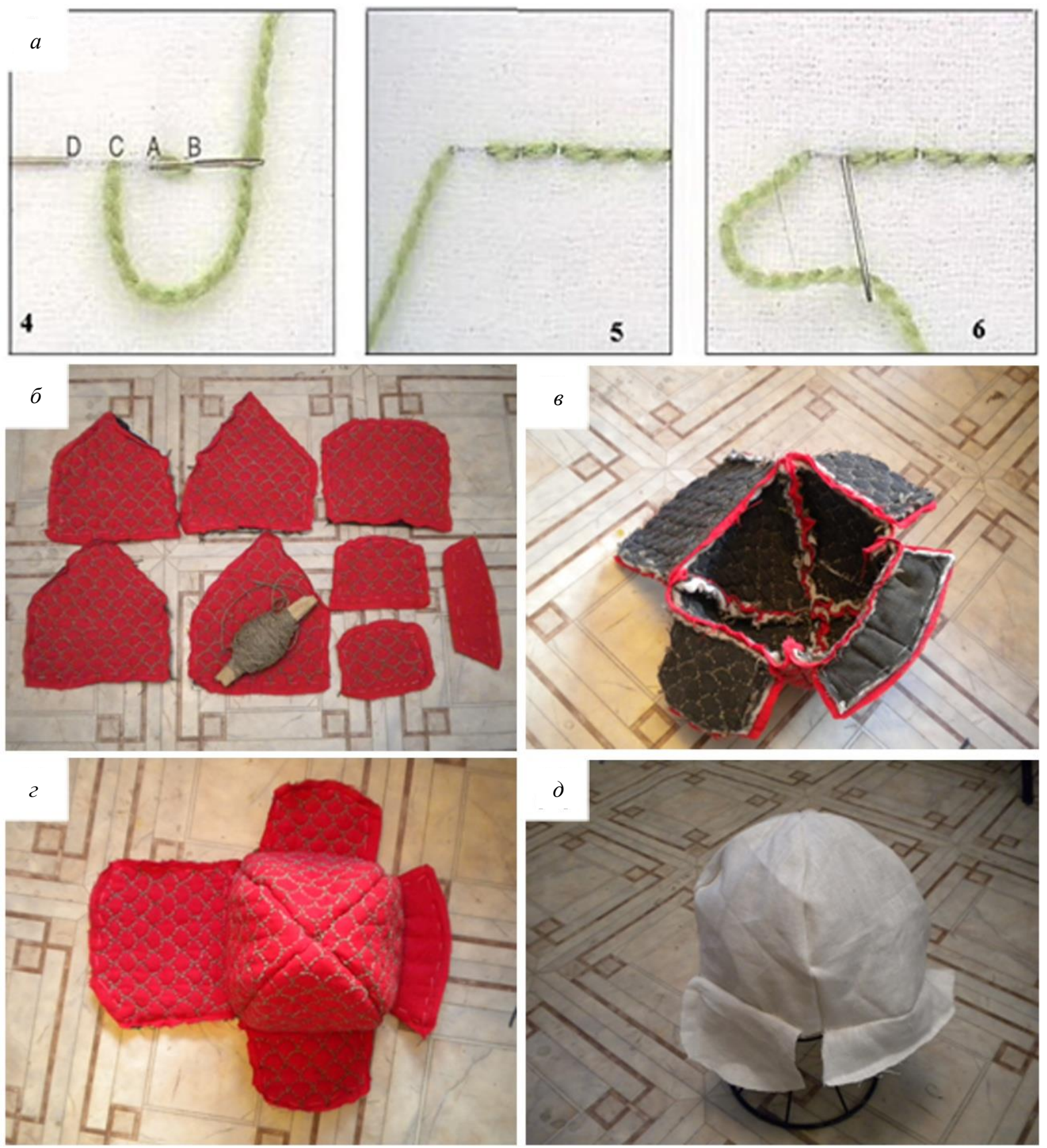

Рис. 3. Шов, простежка, сборка:

а) иллюстрации к шву; б) простеганные части основного элемента шапки бумажной; в) собранный основной элемент (вид на изнаночную часть); г) собранный основной элемент (вид на внешнюю часть); д) подклад

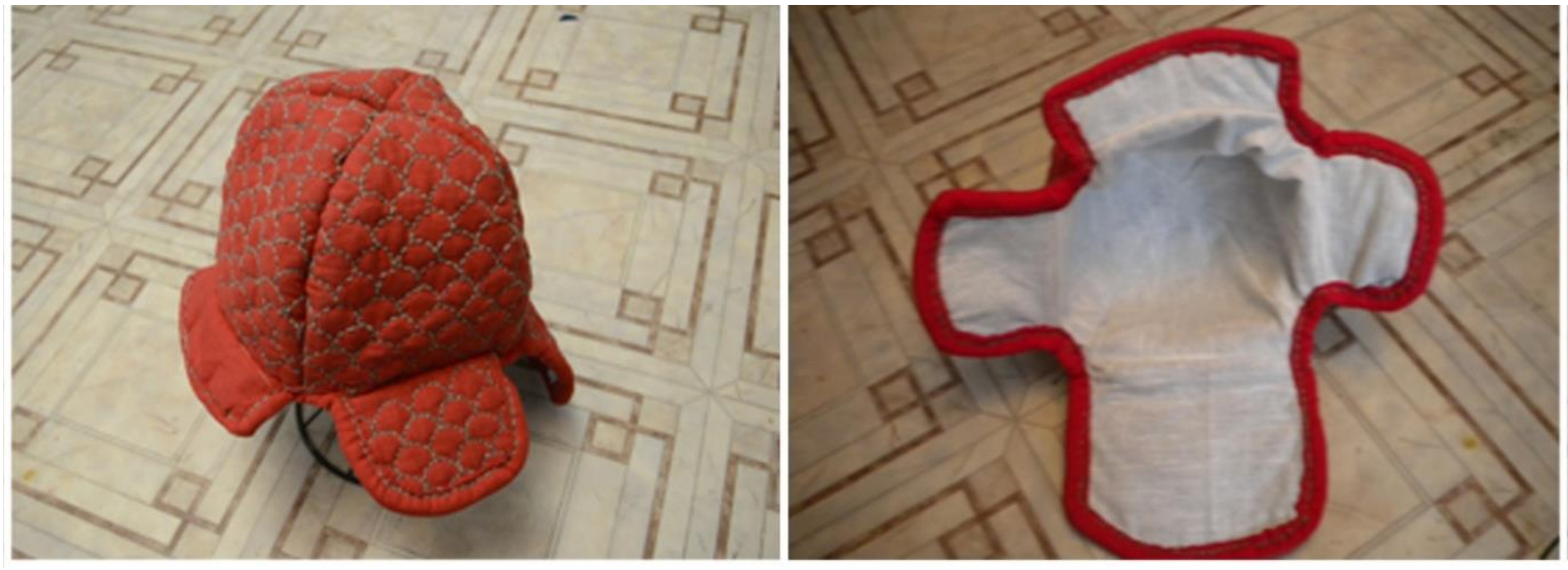

Рис. 4. Готовая стилизация 
Сборка. Наружная часть шапки бумажной сшивается с подкладом. Наметочным швом (в одну нитку очень крупными стежками, после прошивки шов убирается) соединяем по краям и обрабатываем полоской ткани шириной в 10 см, подвернув края к центру (рис. 4).

Реконструкция шапки бумажной максимально соответствует характеристикам исходного образца из Оружейной палаты и подобному типу боевых наголовий в целом. Пошаговая методика реконструкции может быть использована при создании не только шапки бумажной, но и других элементов исторического защитного костюма, где используется технология простегивания. Использовать подобные реплики можно в научных, педагогических и коммерческих проектах, например на музейных выставках, при съемках фильмов, как учебное пособие, для организации мероприятий и т.д.

\section{ЛИТЕРАТУРА}

1. Москвин А.Ю., Москвина М. А. Реконструкция одежды: сущность, проблемы, перспективы // Молодой ученый. 2014. № 3. С. 334-337.

2. Висковатов А. В. Историческое описание одежды и вооружения российских войск : в 19 ч. 2-е изд. СПб. : Тип. «В.С. Балашев и Ко», 1899. Ч. 1.

3. Солнцев Ф.Г. Древности Российского государства. Шапка Куячная. М., 1853.

4. Герберштейн С. Записки о Московитских делах. СПб. : Тип. А.С. Суворина, 1908.

5. Шиндлер O.В. Русские шлемы XVI века // История военного дела: исследования и источники. 2016. T. VIII. URL: http://www.milhist.info/ 2016/05/10/schindler_3 (дата обьращения: 05.10.2016).

6. Опись Московской Оружейной палаты. Ч. 3, кн. 2. Броня. М. : О-во распространения полезных книг, 1884.

7. Вышивка : уроки. URL: http://hand-made-granary.narod.ru/Em_lesson001.html

Ovanenko Ivan V. National Research Tomsk State University (Tomsk, Russia). E-mail: ovanenko_iv@gmail.com THE EXPERIENCE OF THE RECONSTRUCTION OF A HISTORICAL OUTFIT ON A CASE OF «PAPER HELMET»

Keywords: armor; combat header; paper helmet; full-scale reconstruction; step-by-step method.

The article is devoted to the creation of step-by-step method of full-scale historical reconstruction of "paper helmet". The topicality of historical reconstructions is caused both by the necessity of studying history and by the increased need of society in visualization of history. The most complete is a full-scale reconstruction which allows you to restore not only the shape of the object, but also its manufacturing technology. The scientific research value of full-scale reconstruction is the verification of various theories. In order to adequately reproduce the historical prototype, it is necessary to have a reliable source and methodological base. Very important information about the "paper helmet" is contained in the works of A.V. Viskovatov, F.G. Solntsev, S. Gerberstein. According to A.V. Viskovatov "A paper hat is a headdress performing protective functions. They were quilted hats made of cloth, silk or paper (cotton) fabrics, with thick cotton or hemp filling". S. Gerberstein mentions "paper helmet" in this way: "By the protective properties, the "hat" was similar to the tegilyay - it did not give reliable protection, but nevertheless, according to the testimony of contemporaries, it could hold an arrow".

The article describes a step-by-step methodology for creating a full-scale reconstruction which includes:

A) Material selection. For the selection of materials, the main criterion was the description of Viskovatov and the search for modern analogues. The author chose the materials: cotton, linen, cotton fabrics, burlap, woolen threads treated with wax.

B) Pattern of details. A pattern consisting of eight parts (four parts of the subtriangle form are assembled with a dome of a "paper helmet", two parts are used to make sidewalls, one part for a visor and another one - for neck protection), was constructed according to F.G. Solntsev taking into account the parameters of the author's head.

C) Stitch detail. The form of quilting (a semicircle with a radius of $12.5 \mathrm{~mm}$ in staggered order) and size of the stitches are based on the exhibit No. 4463 "Paper Helmet" from The Armory Chamber.

D) Assembling the parts. The stitching of the main parts and the lining was done according to the illustration of F.G. Solntsev.

Reconstruction of the "paper helmet" corresponds to the characteristics of the original sample from The Armory Chamber and to a similar type of combat headers generally. In the course of the study were checked the F.G. Sontsev's illustrations and the protective properties of the replica. The created step-by-step method of full-scale historical reconstruction can be used not only for creating a "paper helmet", but also for creating other elements of a historical protective suit, where textile materials and quilting technology are used. Using such replicas is possible in scientific, pedagogical and commercial projects, for example: at museum exhibitions, when shooting movies, as a training manual, for organizing events, etc.

\section{REFERENCES}

1. Moskvin, A.Yu. \& Moskvina, M.A. (2014) Rekonstruktsiya odezhdy: sushchnost', problemy, perspektivy [Reconstruction of clothes: essence, problems, prospects]. Molodoy uchenyy.3(62). pp. 334-337.

2. Viskovatov, A. V. (1899) Istoricheskoe opisanie odezhdy i vooruzheniya rossiyskikh voysk [Historical description of clothing and weapons of Russian troops]. 2nd ed. St. Petersburg: V. S. Balashev i Ko. Pt.1.

3. Solntsev, F.G. (1853) Drevnosti Rossiyskogo gosudarstva. Shapka Kuyachnaya [Antiquities of the Russian State. Armoured covers]. Moscow: [s.n.].

4. Gerbershteyn, S. (1908) Zapiski o Moskovitskikh delakh [Notes on the Muscovite affairs]. St. Petersburg: A.S. Suvorin.

5. Shindler, O.V. (2016) Russkie shlemy XVI veka [Russian helmets of the 16th century]. [Online] Available from: http://www.milhist.info/2016/05/10/schindler_3 (05.10.2016).

6. Yakovlev, L.P. (ed.) (1884) Opis' Moskovskoy Oruzheynoy palaty [Inventory of the Moscow Armory Chamber]. Part 3(2). Moscow: Obshchestvo rasprostraneniya poleznykh knig.

7. Anon. (n.d.) Vyshivka [Embroidery]. [Online] Available from: http://hand-made-granary.narod.ru/Em_lesson001.html. 